\title{
Evaluation of Surface Characteristics and Physical Properties on Biodegradable Magnesium-Calcium Alloys by Anodic Oxidation
}

\author{
J.H. KIM ${ }^{a}$, J.Y. $\mathrm{LEE}^{a, b}$, H.S. YANG ${ }^{a}$, S.W. PARK ${ }^{a}$, H.P. $\operatorname{Lim}^{a}$, G.J. OH${ }^{c}$ AND K.D. YUN ${ }^{a} *$ \\ ${ }^{a}$ Chonnam National University, School of Dentistry, 61186 Gwangju, Republic of Korea \\ ${ }^{b}$ Seoul Narin Dental Clinic, 62247 Gwangju, Republic of Korea \\ ${ }^{c}$ Chonnam National University, RIS Foundation for Advanced Biomaterials, 61186 Gwangju, Republic of Korea
}

\begin{abstract}
The purpose of this study was to determine the effect of calcium (Ca) on the surface characteristics and physical properties of magnesium-calcium alloys after anodization. A novel binary alloy $\mathrm{Mg}-x \mathrm{Ca}$ (in which $x=0.5$, 1 , or 5 wt. \%) was cast by combining magnesium (99.9\%) and calcium (99.9\%) in an argon gas (99.99\%) atmosphere. A magnesium alloy rod having a diameter of $15 \mathrm{~mm}$ was cut into discs, each $2 \mathrm{~mm}$ thick. The specimens were subjected to anodic oxidation at $120 \mathrm{~V}$ for 15 minutes at room temperature in an electrolyte solution consisting of calcium gluconate, sodium hexametaphosphate, and sodium hydroxide. Surface and cross-sectional morphological changes were observed using scanning electron microscopy, and the microstructures and phases were detected by means of X-ray diffraction. Hardness and surface roughness were assessed by means of a Vickers hardness tester and a surface roughness meter, respectively. The results show that the physical properties of these magnesiumcalcium alloys have been improved, because it was possible to control the dissolution rate according to the amount of calcium added.
\end{abstract}

DOI: 10.12693/APhysPolA.129.736

PACS/topics: 87.85.jj, 87.85.jc

\section{Introduction}

The frequency of surgical treatments for bone-related disorders, including orthognathic surgery, has markedly increased in response to the rising number of injuries related to transportation and industrial disasters, longer life expectancies, and the growing interest in a more aesthetic appearance and in enhancing one's quality of life. In the case of orthopedic surgery, noble metals such as stainless steel, titanium alloys, and cobalt-chrome alloys are now commonly used in the manufacture of dental materials, including bone screws, bone plates, bone fixation devices, artificial joints, and dental implants [1].

These metals are considered appropriate for medical use because they are relatively inert and semi-permanent in the body, and shorten the postoperative recovery [2]. After dental implants containing these semi-permanent metals have properly adhered to the bone, they must be removed in a secondary procedure, which can cause pain and chronic infection. Moreover, these implants may distort the images obtained on screening devices, can influence the mobility of bone structures, and may fracture as a result of sustained overload.

In an effort to overcome these shortcomings of inactive metals, researchers have sought to develop absorbable metals that will naturally degrade after the damaged bone has recovered [1]. Magnesium $(\mathrm{Mg})$, which is currently used in absorbable dental implants, is considered

*corresponding author; e-mail: ykd@jnu.ac.kr a proper candidate for absorbable materials. Because it is found naturally in the human body and is therefore non-toxic. In addition, this mineral has a low density, a high level of mechanical strength and fracture toughness and superior biological compatibility [3]. About 50\% of $\mathrm{Mg}$ in the human body is present in the bone tissue [4], where it helps to increase the growth and strength of bone [5]. Mg has a low modulus of elasticity when compared with other metals, which may help prevent the stress shield phenomenon, which is possibly a major cause of implant failure [6-10]. However, one of the shortcomings of $\mathrm{Mg}$ is that it produces hydrogen gas while it dissolves and corrodes in the body, often before the damaged areas are fully recovered, causing its mechanical properties to become degraded [6, 11-14] The degraded mechanical strength of $\mathrm{Mg}$, due to corrosion, decreases the support capability of $\mathrm{Mg}$ implants, which compromises implant function in vivo.

Rapid control of the biodegradation rate in vivo is desirable, and efforts to achieve this goal include the use of alloys, surface coating, and refining [15]. Element alloying is one way to develop a Mg-based biodegradable material in vivo [16, 17]. Adding alloyed elements is expected to improve implant performance by enhancing its mechanical properties and increasing its resistance to corrosion [18, 19]. The Mg-based alloys used for biodegradable materials should also be non-toxic [20]. Calcium $(\mathrm{Ca})$ has also been reported to be a non-toxic material in the human body [21, 22]. Mg-Ca alloys are also advantageous in that they help recovery of skeletal structures by releasing $\mathrm{Mg}^{2+}$ and $\mathrm{Ca}^{2+}$ ions [20]. 
Mg-Ca alloys are also suitable dental implant materials in terms of their biodegradability [23-25], the virtue of $\mathrm{Mg}$ as biodegradable implant material being its superior mechanical properties and controllable corrosion resistance [26]. The standard electrode potential of $\mathrm{Mg}$ is as low as $-2.363 \mathrm{~V}$ (relative to the normal hydrogen electrode [NHE]), and it rapidly corrodes in air or solutions without surface treatment. Therefore, surface coating has emerged as an important means of improving corrosion resistance $[27,28]$. Anodizing refers to the process of forming an oxygen layer when electrolysis is performed and oxidation occurs at the anode [6, 29-31]. This method is very effective in preventing the corrosion of $\mathrm{Mg}$ alloys, which have high surface reactivity, owing to high corrosion resistance, wear resistance, and electric resistance [31-35].

In this study, we have produced binary alloys consisting of $\mathrm{Mg}-x \mathrm{Ca}(x=0.5,1,5 \mathrm{wt} . \%)$ and anodized them at $120 \mathrm{~V}$ for 15 minutes to assess methods for controlling their rapid rate of biodegradation in vivo. After anodization, the surface properties and physical properties of these alloys were observed and analyzed. We also analyzed their microcrystalline structure by means of highresolution X-ray diffractometry.

\section{Materials and methods}

\subsection{Specimen preparation}

We have produced binary alloys using magnesium (Mg) (99.9\%, Sincere East, China) and calcium (Ca) (99.9\%, Junsei Chemical, Japan). The required amounts of $\mathrm{Mg}$ and $\mathrm{Ca}$ were put into a vacuum arc remelting furnace (Ace Vacuum, Korea) at 700 to $810^{\circ} \mathrm{C}$ and were melted by induction heating in a vacuum at $300 \mathrm{~A}$. The molten metal was left untreated to allow stabilization for 45 minutes under melting conditions, after which it was poured into a mold that had been preheated at $200{ }^{\circ} \mathrm{C}$ for 2 hours. A magnesium rod $15 \mathrm{~mm}$ in diameter was then cut into $2 \mathrm{~mm}$-thick discs using a ISOMET 5000 linear precision saw (Buehler, USA) for surface analysis and to determine their physical properties. All specimens were polished using Labopol-5 grinder (Struers, Denmark) with silicon carbide abrasive papers, ranging from very rough to very fine (\#600 to \#2000), and then underwent final wet grinding with a $0.3 \mu \mathrm{m} \alpha$ alumina $\left(\mathrm{Al}_{2} \mathrm{O}_{3}\right)$ suspension. For ultrasonic cleaning, the prepared specimens were immersed in distilled water for 3 minutes. Any remaining organic compounds and impurities on the disc surfaces were removed to minimize their possible effects, and the specimens were then dried and stored at room temperature.

\subsection{Experimental groups}

The anodized magnesium-calcium alloy specimens were divided into three groups according to calcium content $(0.5,1$, or 5 wt. $\%)$ : $\mathrm{Mg}-0.5 \mathrm{Ca}, \mathrm{Mg}-1 \mathrm{Ca}$, and $\mathrm{Mg}-5 \mathrm{Ca}$. Anodized pure $\mathrm{Mg}$ was used as the control (Table I).

\section{TABLE I}

Experimental groups.

\begin{tabular}{c|c|c|c}
\hline \hline \multirow{2}{*}{$\begin{array}{c}\text { Surface } \\
\text { treatment }\end{array}$} & Material & \multicolumn{2}{|c}{ Composition [wt.\%] } \\
\cline { 3 - 4 } & & $\mathrm{Ca}$ & $\mathrm{Mg}$ \\
\hline \multirow{3}{*}{$\begin{array}{c}\text { Anodic } \\
\text { oxidation }\end{array}$} & Pure $\mathrm{Mg}-0.5 \mathrm{Ca}$ & - & Bal. \\
& $\mathrm{Mg}-1 \mathrm{Ca}$ & 1 & Bal. \\
& $\mathrm{Mg}-5 \mathrm{Ca}$ & 5 & Bal. \\
& & & Bal.
\end{tabular}

\subsection{Anodizing process}

All specimens were treated in a 4-step process involving a 3-minute ultrasonic cleaning in distilled water using JAC-2010 ultrasonic cleaner (Kodo, Korea), acidification, anodizing, and sealing. The specimens were then cleaned three times for 10 seconds, each time using reverse osmosis to wash off the remaining solution. A VUPOWER-AK6003 DC power supply (ICAN, Korea) was used as the supply of electrical current, and the specimens were anodized, with the magnesium serving as the anode and a platinum plate $\left(3 \times 4 \times 0.1 \mathrm{~mm}^{3}\right)$ serving as the cathode, with a distance of $30 \mathrm{~mm}$ between the anode and the cathode. The electrolyte solution consisted of calcium gluconate $(4 \mathrm{~g} / \mathrm{L})$, sodium hexametaphosphate $\left(\left(\mathrm{NaPO}_{3}\right)_{6}\right)(3 \mathrm{~g} / \mathrm{L})$, and sodium hydroxide $(\mathrm{NaOH})(6 \mathrm{~g} / \mathrm{L})$. The solution inside the tank remained at room temperatures $\left(20-25^{\circ} \mathrm{C}\right)$ as the water had circulated. A Scr-rectifier DC purifier (Hyun Sung Electronic, Korea) was used, and anodization (Fig. 1) was carried out for 15 minutes at $120 \mathrm{~V}$. After being anodized, the specimens were submerged in $100^{\circ} \mathrm{C}$ distilled water for sealing and were then dried by blowing air.

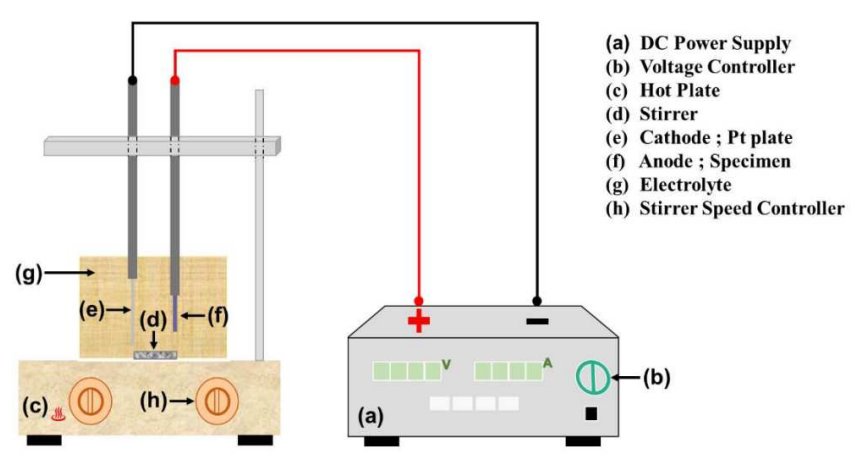

Fig. 1. Schematic diagram of the anodizing oxidation apparatus.

\subsection{Surface analysis of anodized specimens}

After platinum coating using an E-1030 Ion Sputter apparatus (Hitachi, Japan), a field emission scanning electron microscopy (FE-SEM) using a S-4700 microscope (Hitachi, Japan) was used to observe the surface of the anodized Mg-Ca based alloys. Energy dispersive spectroscopy (EDS) was done using a XFlash Detector 5030 (Bruker Nano, Germany) for elemental analysis. 


\subsection{Surface roughness}

A DIAVITE DH-7 two-dimensional contact stylus profilometer (Asmeto AG, Switzerland) was used to measure the mean surface roughness $(\mathrm{Ra})$ for the anodized pure $\mathrm{Mg}$ and the three $\mathrm{Mg}-\mathrm{Ca}$ alloys. All specimens were measured 12 times, and the mean roughness value was calculated as the difference between the maximum and minimum values.

\subsection{Surface hardness}

To assess the mechanical properties of the anodized $\mathrm{Mg}-\mathrm{Ca}$ alloys, surface hardness was measured using a model MHV-2000/s Vickers hardness tester (Huatec, China). Each specimen was measured 12 times to minimize errors, and mean values were calculated with 10 results, leaving out the maximum and the minimum measurements. A diamond indentor was used to measure the indentations made on each specimen at a load of $300 \mathrm{~g}$.

\subsection{Crystal structure analysis}

The microcrystalline structure of the anodized Mg$\mathrm{Ca}$ alloys was analyzed using high resolution X-ray diffractometry using an X'pert PRO multi-purpose X-ray diffractometer (PANalytical, Netherlands). The analysis was performed at the speed of $2^{\circ}$ per minute using X-rays produced at $40 \mathrm{kV}$ and $35 \mathrm{~mA}$. The $2 \theta$ was varied within the range of $20-80^{\circ}$ and the diffraction surface was presented by a JCPDS card (09-0432).

\subsection{Anodic oxide film thickness}

Anodized Mg rod specimens were embedded in Caulk acrylic resin (Dentsply, Germany) and the center of the specimens were cut using an ISOMET 5000 linear precision saw (Buehler, USA). The surface of the prepared specimens was polished to a high number using graded low number $(\# 600)$ to high number $(\# 2000)$ silicon carbide abrasive papers using a Labopol-5 grinder (Struers, Denmark), followed by wet grinding using a $0.3 \mu \mathrm{m}$ alpha alumina $\left(\mathrm{Al}_{2} \mathrm{O}_{3}\right)$ suspension. For ultrasonic cleaning, the prepared specimens were immersed in distilled water for 3 minutes. Anodic oxide film thickness was measured by FE-SEM.

\subsection{Statistical analysis}

IBM SPSS Statistics version 21 software (SPSS, Chicago, IL, USA) was used for statistical analyses. The values were statistically analyzed by one-way ANOVA followed by Tukey's honest significance test and the Bonfferoni test to assess statistical significance. All comparisons were considered statistically significant if $p<0.05$.

\section{Results and discussion}

\subsection{Analysis of surface coating by anodizing}

Using SEM, we have examined the microstructures of the coatings formed on the alloy surfaces. The representative images can be seen in Fig. 2. As expected, the addition of $\mathrm{Ca}$ has resulted in denser and smaller crystal grains, because Ca effectively refines the grains of $\mathrm{Mg}$. Moreover, since the solubility limit of $\mathrm{Ca}$ in $\mathrm{Mg}$ is relatively low (0.98 wt.\%), Ca is released during solidification, which leads to supersaturation of $\mathrm{Ca}$ at the surface. The remaining solute suppresses the growth of the grains [36].

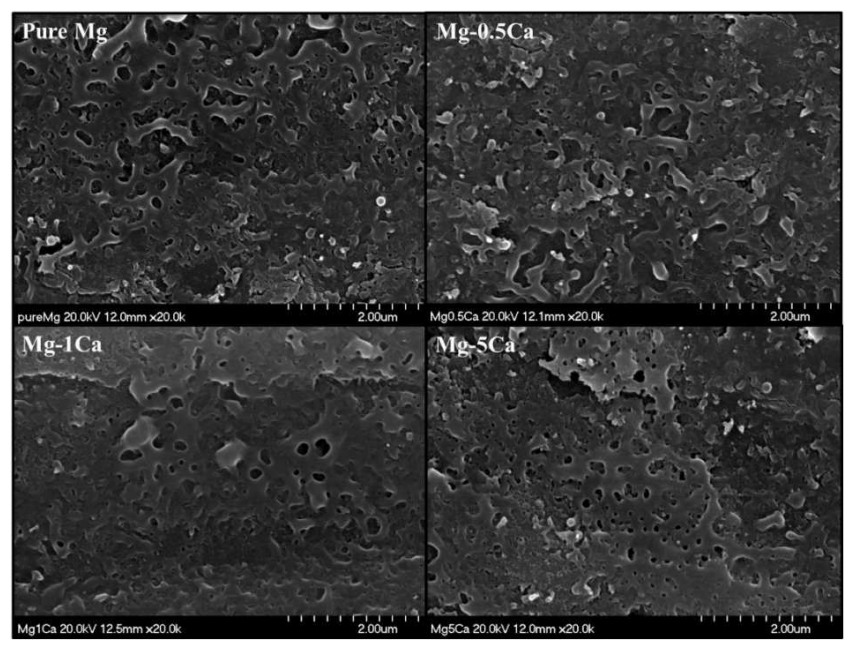

Fig. 2. SEM photographs of pure $\mathrm{Mg}$ and $\mathrm{Mg}$-Ca alloys after anodizing treatment.

\subsection{Surface roughness}

Figure 3 graphically depicts the results of surface roughness measurements conducted to examine the effect of $\mathrm{Ca}$ in each alloy. Studies have shown that anodization with an electrolyte solution containing $\mathrm{NaOH}$ and $\mathrm{Na}_{3} \mathrm{PO}_{4}$ had markedly increased the roughness [3740]. The highest and lowest roughness values had had $\mathrm{Mg}-5 \mathrm{Ca}$ alloy $(0.353 \mu \mathrm{m})$ and the pure $\mathrm{Mg}$, respectively. The increasing roughness with the increasing $\mathrm{Ca}$ content most likely reflects the formation of a precipitate during anodizing with the electrolyte solutions containing $\mathrm{NaOH}$ and $\mathrm{Na}_{3} \mathrm{PO}_{4}$, at constant current and voltage.

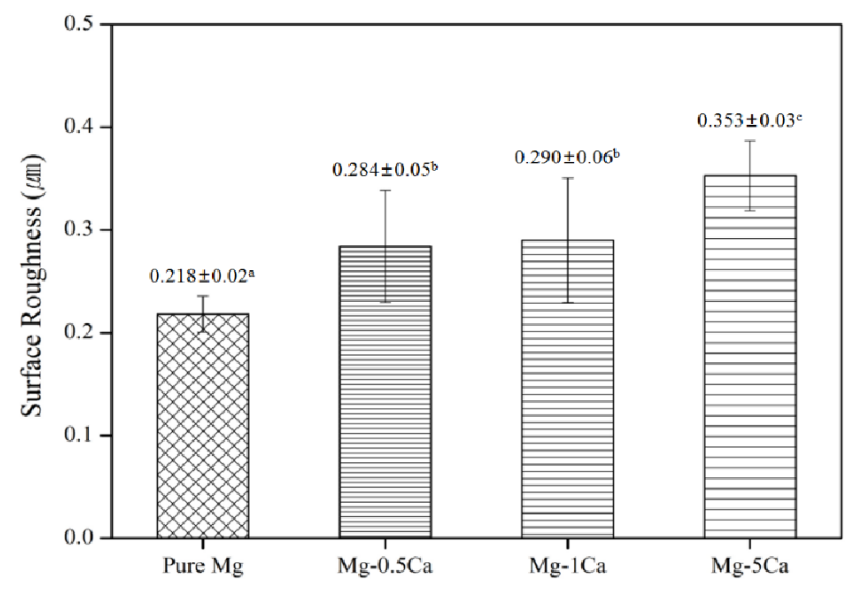

Fig. 3. Graphs of surface roughness ( $\mathrm{Ra}$ ) of pure $\mathrm{Mg}$ and $\mathrm{Mg}-\mathrm{Ca}$ alloys coated through anodization $(n=10)$. The letters a, b, c denote significant difference at $p<0.05$. 


\subsection{Surface hardness}

Figure 4 graphically presents the results of Vickers hardness measurements. Increasing $\mathrm{Ca}$ content has led to a progressively greater surface hardness, with an evident excellent mechanical strength. The $\mathrm{Mg}-5 \mathrm{Ca}$ alloy displayed the highest level of hardness, which was 1.7 times higher than that of the pure Ca-free $\mathrm{Mg}$ specimens. This finding apparently represents intermetallic reinforcing due to the added $\mathrm{Ca}$; an oxidized layer is formed to create an intermetallic compound, $\mathrm{Mg}_{2} \mathrm{Ca}$, which is formed of fine particles and has a high melting point. This layer substantially improves the physical properties of the $\mathrm{Mg}-5 \mathrm{Ca}$ alloy [39]. It is likely that the addition of $\mathrm{Ca}$ has progressively increased the hardness of the $\mathrm{Mg}-\mathrm{Ca}$ alloys. Hardness can affect the phase distribution. The size reduction as well as the increased overall amount of secondary phase during the solidification, is likely the result of $\mathrm{Mg}_{2} \mathrm{Ca}$ precipitates at the interface between the substrate and the particles [38].

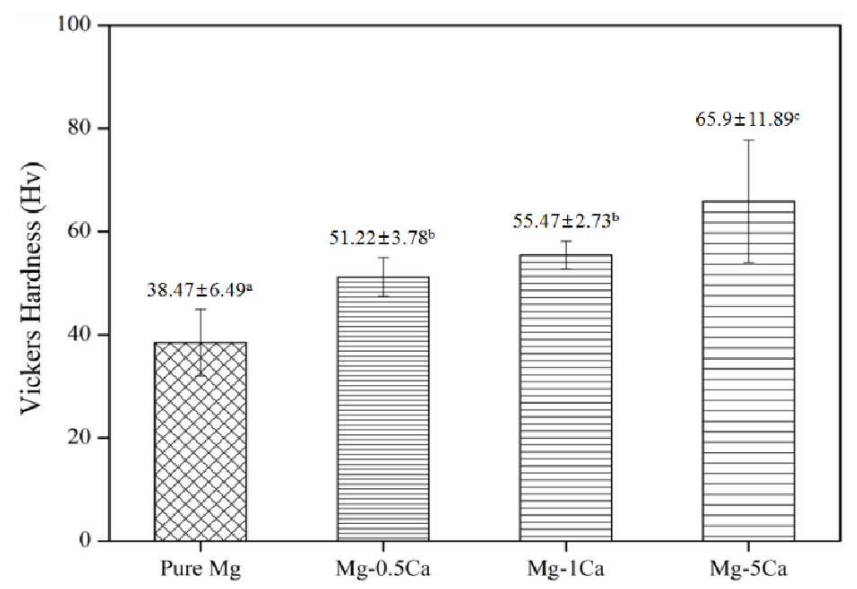

Fig. 4. Surface hardness of anodized pure $\mathrm{Mg}$ and Mg-Ca alloys $(n=10)$ obtained by Vicker's hardness test. The letters $a, b, c$ denote significant difference at $p<0.05$.

\subsection{Crystalline analysis}

Representative X-ray diffraction patterns of anodized pure $\mathrm{Mg}$ and the $\mathrm{Mg}$-Ca alloy are shown in Fig. 5. Every material group has shown a phosphorus diffraction peak on surface, which was probably caused by sodium hexametaphosphate $\left(\left(\mathrm{NaPO}_{3}\right)_{6}\right)$ formed during the anodizing process and by phosphoric acid solution $\left(\mathrm{H}_{3} \mathrm{PO}_{4}\right)$ formed in the preconditioning process. In addition, unlike pure $\mathrm{Mg}$ sample, all $\mathrm{Mg}-\mathrm{Ca}$ alloys have displayed $\mathrm{Ca}$ and $\mathrm{Mg}_{2} \mathrm{Ca}$ phases, with peak intensity from the (400) surface, increasing with the increase of Ca content. This is considered to be a result of increasing amount of Ca, which satisfies the diffraction condition at the surface layer.

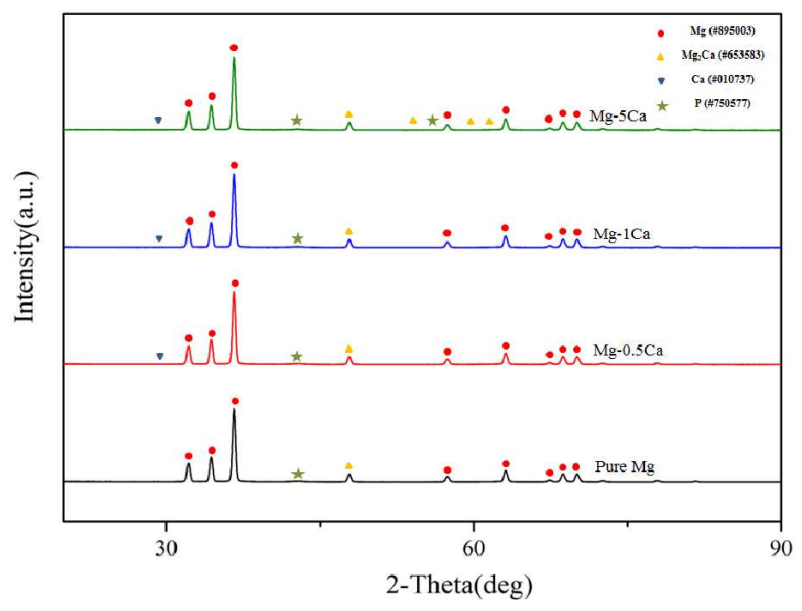

Fig. 5. X-ray diffraction patterns of anodized $\mathrm{Mg}-\mathrm{Ca}$ alloys.

\subsection{Anodized layer thickness}

Figure 6 includes representative FE-SEM images of the coated layer of anodized alloys containing various amounts of Ca. The thickness of the oxidation layer has increased with the amount of $\mathrm{Ca}$, with the thickness of the $\mathrm{Mg}-5 \mathrm{Ca}$ alloy being the greatest. Because $\mathrm{Ca}$ is effective in preventing the alloy oxidation during casting or annealing and also plays a role as a grain refiner, the oxidation layer has probably formed a fine film (averaging $5.3 \pm 0.79 \mu \mathrm{m}$ ) with the addition of $\mathrm{Ca}$, as the anodizing layer became thicker. Figure 7 displays EDS images, showing the linear scans along the anodized layers. Both phosphorus and calcium were more widely distributed on the outer layer than on the inner layer of the anodized surfaces. The distribution of Ca on the outer layer has increased with increasing concentration of $\mathrm{Ca}$ in the alloys.

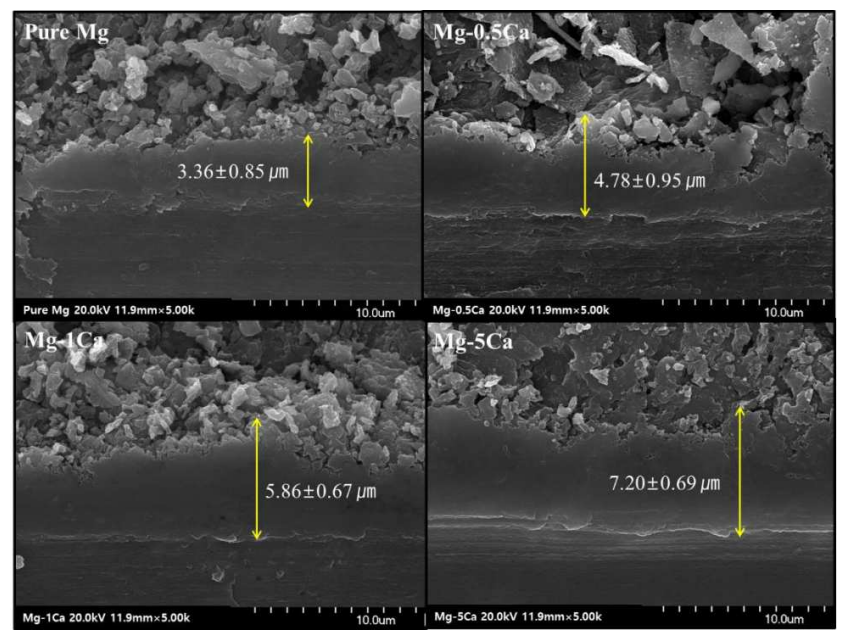

Fig. 6. Cross-sectional SEM images of layers formed on the specimens. 


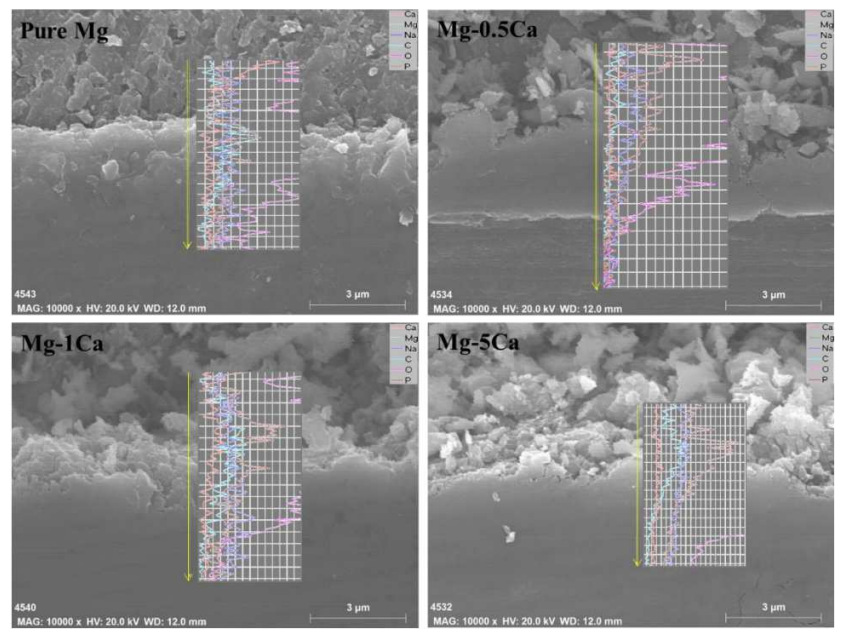

Fig. 7. EDS line scanning profile images of the specimen membranes.

\section{Conclusions}

We have evaluated the effects of different amounts of $\mathrm{Ca}$ on anodized $\mathrm{Mg}-\mathrm{Ca}$ alloys by examining the surface characteristics and physical properties of these alloys in vivo. With the addition of $\mathrm{Ca}$ a fine film layer is formed at the anodized surface, which improves the corrosion resistance. Addition of Ca makes the particle size finer and markedly increases the number of secondary phase precipitates on the surface of alloys. Due to the grain refinement of $\mathrm{Ca}$, the intermetallic $\mathrm{Mg}_{2} \mathrm{Ca}$ is evenly distributed on the surface. The increase of the amount of Ca has correlated with the increasing hardening of the binary alloys. In addition, at a constant current and voltage, surface roughness has increased with the increasing $\mathrm{Ca}$ content, owing to precipitates formed during the anodizing process using electrolyte solutions containing sodium hydroxide $(\mathrm{NaOH})$ and phosphoric acid $\left(\mathrm{H}_{3} \mathrm{PO}_{4}\right)$. The contents of $\mathrm{Ca}$ and phosphate, which satisfied the diffraction condition were increased by the sodium hexametaphosphate $\left(\left(\mathrm{NaPO}_{3}\right)_{6}\right)$ electrolyte solution, which was used for anodizing and preconditioning, and by the phosphoric acid $\left(\mathrm{H}_{3} \mathrm{PO}_{4}\right)$ solution. Finally, the addition of Ca has helped the grain refining process, with the formation of a dense film layer. As Ca content increased, both anodized layers had became thicker. Anodized pure $\mathrm{Mg}$ and $\mathrm{Mg}-\mathrm{Ca}$ alloys have displayed improved physical properties as the Ca content increased, enabling the control of the speed of dissolution. The results demonstrate the applicability of $\mathrm{Mg}-\mathrm{Ca}$ alloys as the biodegradable implant material.

\section{Acknowledgments}

This research was supported by Basic Science Research Program through the National Research Foundation of Korea (NRF) funded by the Ministry of Education, Science and Technology (NRF-2012R1A1A1043434).

\section{References}

[1] H.K. Seok, Y.C. Kim, P.R. Cha, G.S. Han, Y.Y. Kim, S.Y. Cho, S.J. Yang, Korean J. Met. Mater. 22, 29 (2009).

[2] Y. Song, S. Zhang, J. Li, C. Zhao, X. Zhang, Acta Biomater. 6, 1736 (2010).

[3] H.G. Seiler, H. Sigel, A. Sigel, Handbook on Toxicity of Inorganic Compounds, Marcel Dekker 1988.

[4] R.J. Elin, Clin. Chem. 33, 1965 (1987).

[5] H. Zreiqat, C.R. Howlett, A. Zannettino, P. Evans, G. Schulze-Tanzil, C. Knabe, M. Shakibaei, J. Biomed. Mater. Res. 62, 175 (2002).

[6] M.P. Staiger, A.M. Pietak, J. Huadmai, G. Dias, Biomaterials 27, 1728 (2006).

[7] E.P.D. Garmo, J.T. Black, R.A. Kohser, DeGarmo's Materials and Processes in Manufacturing, John Wiley \& Sons 2011.

[8] L. J. Gibson, M.F. Ashby, Cellular Solids: Structure and Properties, Cambridge University Press 1997.

[9] J.W. Choi, Y.M. Kong, H.E. Kim, I.S. Lee, J. Am. Ceram. Soc. 81, 1743 (1998).

[10] T.V. Thamaraiselvi, S. Rajeswari, Trends Biomater. Artif. Organs. 18, 9 (2004).

[11] F. Witte, V. Kaese, H. Haferkamp, E. Switzer, A. Meyer-Lindenberg, C.J. Wirth, H. Windhagen, Biomaterials 26, 3557 (2005).

[12] C.E. Wen, M. Mabuchi, Y. Yamada, K. Shimojima, Y. Chino, T. Asahina, Scr. Mater. 45, 1147 (2001).

[13] H. Wang, Z.M. Shi, K. Yang, Adv. Mater. Res. 32, 207 (2008).

[14] H.Y. López, D.A. Cortés-Hernández, S. Escobedo, D. Mantovani, Key Engin. Mater. 309, 453 (2006).

[15] J.H. Ji, Y.K. Kim, I.S. Park, H.H. Park, T.S. Bae, M.H. Lee, Korean Soc. Dent. Mater. 39, 26 (2012).

[16] R.B. Figueiredo, T.G. Langdon, J. Mater. Sci. 44, 4758 (2009).

[17] C.C. Koch, R.O. Scattergood, K.M. Youssef, E. Chan, Y.T. Zhu, J. Mater. Sci. 45, 4725 (2010).

[18] B. Denkena, F. Witte, C. Podolsky, A. Lucas, Proc. 5th Euspen Int., 2005, p. 233.

[19] S.G. Lee, Ph.D. Thesis, Pusan National University, 2012.

[20] Z. Li, X. Gu, S. Lou, Y. Zheng, Biomaterials 29, 1329 (2008).

[21] S.G. Steinemann, Corrosion of Surgical Implants in Vivo and in Vitro Tests, John Wiley \& Sons, 1980.

[22] Y. Okazaki, S. Rao, T. Tateishi, Y. Ito, Mater. Sci. Eng. A 243, 250 (1998).

[23] K. Feser, M. Kietzmann, W. Baumer, C. Krause, F.W. Bach, J. Biomater. Appl. 25, 685 (2011).

[24] A. Krause, N. von der Höh, D. Bormann, C. Krause, F.W. Bach, H. Windhagen, A. Meyer-Lindenberg, J. Mater. Sci. Mater. Med. 45, 624 (2010).

[25] F. Witte, Acta Biomater. 6, 1680 (2010).

[26] A. Zakiyuddin, M.Sc. Thesis, Chonnam National University, 2014.

[27] N.T. Kirkland, N. Birbilis, M.P. Staiger, Acta Biomater. 8, 925 (2012). 
[28] C. Lorenz, J.G. Brunner, P. Kollmannsberger, L. Jaafar, B. Fabry, S. Virtanen, Acta Biomater. 5, 2783 (2009).

[29] K.J. Park, M.W. Jung, J.H. Lee, J. Microelectronics Packaging Soc. 17, 71 (2010).

[30] M.H. Kim, Ph.D. Thesis, Pukyong National University, 2010.

[31] D.K. Lee, M.Sc. Thesis, Pusan National University, 2010.

[32] P.B. Srinivasan, C. Blawert, W. Dietzel, Mater. Sci. Eng. A 494, 401 (2008).

[33] Y. Zhang, C. Yan, F. Wang, H. Lou, C. Cao, Surf. Coat. Technol. 161, 36 (2002).
[34] H. Duan, K. Du, C. Yan, F. Wang, Electrochim. Acta. 51, 2898 (2006).

[35] R. Kartika, M.Sc. Thesis, Yeungnam University, 2007.

[36] Q. Zhao, X. Guo, X. Dang, J. Hao, J. Lai, K. Wang, Colloids Surf. B. Biointerfaces 102, 321 (2013).

[37] A.Y. Kim, Ph.D. Thesis, Chonnam National University, 2014.

[38] B.H. Kim, Ph.D. Thesis, Pusan National University, 2012.

[39] J.C. Oh, T. Ohkubo, T. Mukai, K. Hono, Scr. Mater. 53, 675 (2005).

[40] K.I. Kim, Ph.D. Thesis, Chonbuk National University, 2013. 